\title{
Retinoblastoma cT4c TNM Finding v7
}

National Cancer Institute

\section{Source}

National Cancer Institute. Retinoblastoma CT4C TNM Finding v7. NCI Thesaurus. Code C88767.

Intracranial extension not past chiasm. (from AJCC 7th Ed.) 